\title{
Ultra-wide field imaging in peripheral exudative haemorrhagic chorioretinopathy (PEHCR)
}

\author{
Vinod Kumar, Divya Janakiraman, Parijat Chandra, Atul Kumar
}

Dr Rajendra Prasad Centre for Ophthalmic Sciences, All India Institute of Medical Sciences, New Delhi, India

\section{Correspondence to} Dr Vinod Kumar, drvinod_agg@yahoo.com

Accepted 24 November 2015

\section{DESCRIPTION}

An 80-year-old man with hypertension was referred for evaluation of vitreous haemorrhage of 1-week duration in his right eye. The patient had best corrected visual acuity of hand movements and absent light perception in the right and left eyes, respectively. Fundus examination of the right eye revealed dense vitreous haemorrhage. Ultrasonography of the right eye confirmed vitreous haemorrhage. The left eye examination revealed glaucomatous optic atrophy and drusen in the macula.

After informed consent, the patient underwent a 25 -gauge pars plana vitrectomy. After clearing the

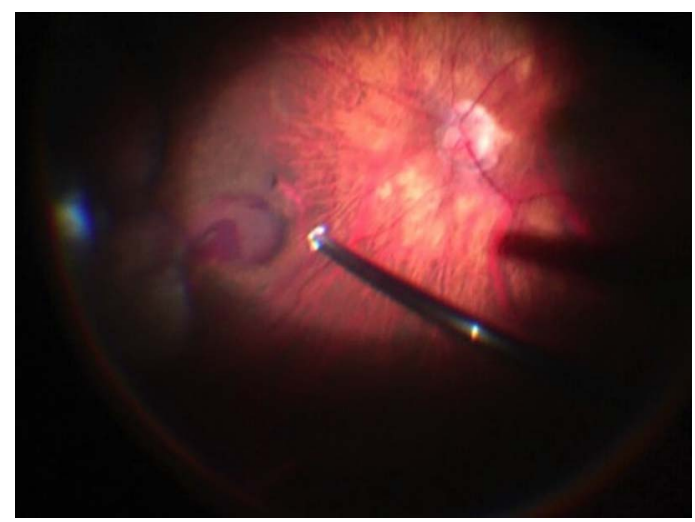

Figure 1 Intraoperative photograph of the nasal periphery of the right eye after clearing of vitreous haemorrhage showing fresh subretinal haemorrhage. The laser was performed around it to prevent its posterior spread.

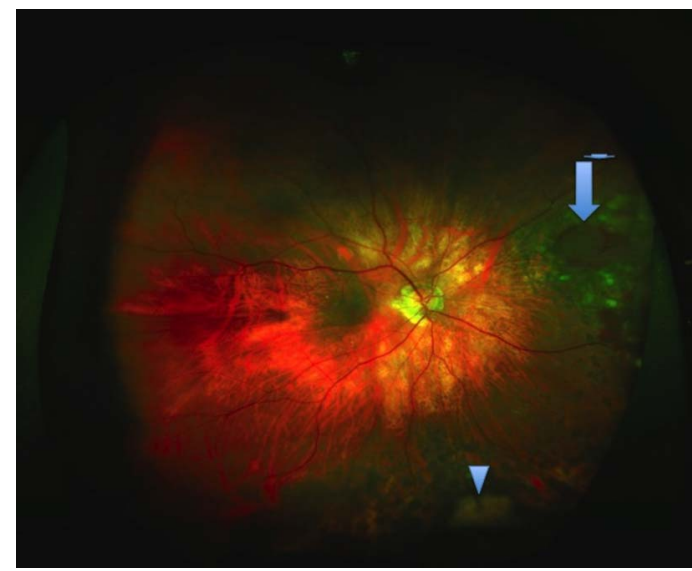

Figure 2 Ultra-wide field pseudo-colour photograph of the right eye showing normal macula. An area of fresh subretinal haemorrhage is noted in the nasal periphery (arrow), while old subretinal blood is noted inferonasally (arrowhead). Laser marks are seen around the posterior aspect of these haemorrhages. vitreous haemorrhage, a fresh nasal subretinal bleed and an old inferonasal subretinal bleed were noted intraoperatively (figure 1). Laser was performed around the nasal fresh subretinal bleed to prevent its posterior spread. The macula was normal.

At 1 week, the patient's vision had improved to 20/30. Ultra-wide field (UWF) imaging using Optos Tx200 (Optos PLC, Dunfermline, Scotland, UK) documented the fresh nasal (figure 2, arrow) as well as old inferonasal subretinal bleeds (figure 2, arrowheads). UWF fluorescein angiography showed blocked fluorescence from the haemorrhage (figure 3, arrowhead). A left steered angiogram,

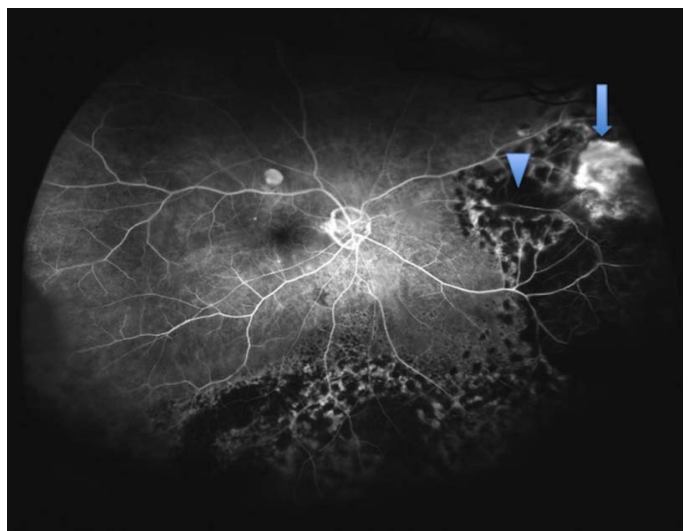

Figure 3 Ultra-wide field fluorescein angiogram (nasally steered photograph) showing laser marks, blocked fluorescence in relation to haemorrhage (arrowhead) and a disciform scar in the nasal periphery (arrow). A small window defect is noted above the fovea, due to retinal pigment epithelium atrophy.

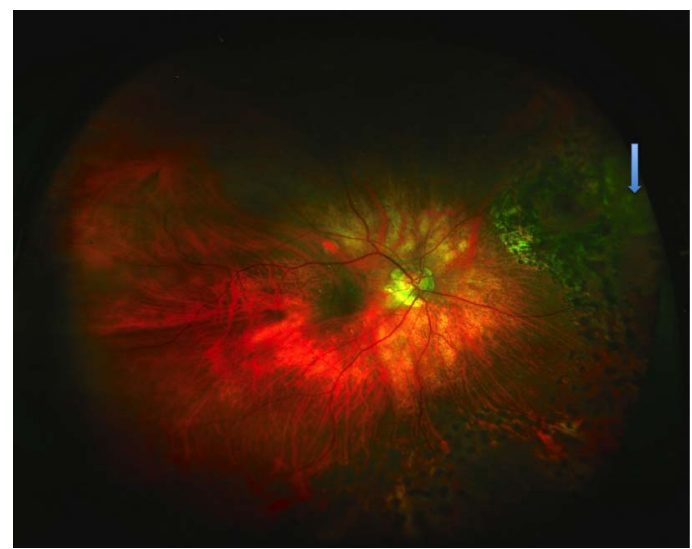

Figure 4 Ultra-wide field pseudo-colour photograph at 1 month of follow-up showing clear media and resolution of the subretinal haemorrhages. The disciform scar is seen as fibrosis (arrow). 
however, showed staining of the peripheral disciform scar (figure 3, arrow). A diagnosis of peripheral exudative haemorrhagic chorioretinopathy (PEHCR) was made. At 1 month, the patient's visual acuity was stable at 20/30 and subretinal haemorrhages had resolved (figure 4). The disciform scar could be seen in the pseudo-colour UWF image (figure 4, arrow).

While conventional cameras can image up to the equator, in PEHCR, the pathology frequently lies anterior to the equator. The peripheral disciform scar in this case was visible only on the left steered images, and that too with the help of UWF imaging. Tsui et $a l^{1}$ first described the use of UWF imaging in PEHCR, and concluded that it was useful in monitoring of suspicious lesions.

Competing interests None declared.

Patient consent Obtained.

Provenance and peer review Not commissioned; externally peer reviewed.

\section{Learning points}

- Peripheral exudative haemorrhagic chorioretinopathy (PEHCR) can present as vitreous haemorrhage in the elderly and should be a differential diagnosis in older patients with vitreous haemorrhage.

- Ultra-wide field imaging helps in diagnosis as well as in monitoring the course of disease and treatment in patients with PEHCR.

- Optos Tx200 covers up to $200^{\circ}$ of the retina and is an important tool in imaging and documentation of anterior retinal lesions.

\section{REFERENCE}

1 Tsui I, Jain A, Shah $\mathrm{S}$, et al. Ultra wide field imaging of peripheral exudative hemorrhagic chorioretinopathy. Semin Ophthalmol 2009;24:25-8.

Copyright 2015 BMJ Publishing Group. All rights reserved. For permission to reuse any of this content visit

http://group.bmj.com/group/rights-licensing/permissions.

BMJ Case Report Fellows may re-use this article for personal use and teaching without any further permission.

Become a Fellow of BMJ Case Reports today and you can:

- Submit as many cases as you like

- Enjoy fast sympathetic peer review and rapid publication of accepted articles

- Access all the published articles

- Re-use any of the published material for personal use and teaching without further permission

For information on Institutional Fellowships contact consortiasales@bmjgroup.com

Visit casereports.bmj.com for more articles like this and to become a Fellow 